\title{
Dilution Effect during Laser Cladding of Inconel 617 with Ni-Al Powders
}

\author{
Ahmed Ali Moosa \\ Department of Production Engineering and Metallurgy \\ University of Technology, Baghdad, Iraq \\ Tel: 964-790-179-3866 E-mail:uot_vicepresident@yahoo.com \\ Mohammed Jasim Kadhim \\ Department of Production Engineering and Metallurgy \\ University of Technology, Baghdad, Iraq \\ Tel: 964-790-549-9306 E-mail: alimohammed1957@yahoo.com
}

\author{
Akeel Dhahir Subhi \\ Department of Production Engineering and Metallurgy \\ University of Technology, Baghdad, Iraq \\ Tel: 964-780-882-7048Ｅ-mail: drengads@yahoo.com
}

\begin{abstract}
In this study, continuous wave $\mathrm{CO}_{2}$ laser with 1.7 and $2 \mathrm{~kW}$ were used to deposit clad layers of premixed powders of either $\mathrm{Ni}-10 \mathrm{wt} \% \mathrm{Al}$ or Ni-30 wt $\% \mathrm{Al}$ onto inconel 617 substrate. Different cladding traverse speeds in the range 1 to $35 \mathrm{~mm} / \mathrm{s}$ were used for premixed clad powder of Ni-10 wt $\% \mathrm{Al}$ and 1.65 to $11.2 \mathrm{~mm} / \mathrm{s}$ for premixed clad powder of $\mathrm{Ni}-30 \mathrm{wt} \% \mathrm{Al}$. Two powder feeding rates were used, 10 and $8.9 \mathrm{gm} / \mathrm{min}$ for premixed clad powders of $\mathrm{Ni}-10 \mathrm{wt} \% \mathrm{Al}$ and $\mathrm{Ni}-30 \mathrm{wt} \% \mathrm{Al}$ respectively. The other laser independent variables were selected to be constant. The results showed that different percentages of area dilution were found ranging from 3.7 to $78.3 \%$ for premixed clad powder of $\mathrm{Ni}-10 \mathrm{wt} \% \mathrm{Al}$ and 6.9 to $41 \%$ for premixed clad powder of $\mathrm{Ni}-30 \mathrm{wt} \%$ Al depending on the laser cladding independent variables used. Furthermore, dilution was affected mainly by cladding traverse speeds.
\end{abstract}

Keywords: Laser cladding, Dilution, Inconel 617, Ni-Al powders, Independent variables

\section{Introduction}

There has never been a period in history during which the evolution of materials and products has been faster and the range of their properties more varied than today (Nenadovć, 2002). The traditional forte of the materials scientist has been the control of the physical, chemical and mechanical properties to produce an ensemble of useful product profiles. With continually improving understanding of chemistry - structure - property relationships, incrementally improved materials steadily appear (Das and Davis, 1988). Lasers have greatly contributed to major fields of science, technology and medicine since the first success in laser applications in 1960 (Maiman, 1960). Laser surface treatments under selected variables have been proven to improve the surface properties in several ferrous and nonferrous alloys. Laser cladding is one of laser surface treatments that required overlay one metal or alloy with another, producing a sound interfacial bond with minimum dilution of the cladding metal or alloy with substrate material (Yang, 1999; Manna, Majumdar, Chandra, Nayak and Dahotre, 2006).

In industrial gas turbine engine manufacturing industry, materials used are specifically to meet the needs of the hot gas path components exposed to the most severe operating conditions; where high temperature creep, tensile strength, ductility and oxidation resistance are required to withstand the loadings imposed. Replacement of the degraded parts is a successful solution but costly. Therefore, repairing the degraded parts for example turbine blades tips is the most important process with accepted cost. Laser cladding with selected clad layers is the most important repairing process distinguished with controlled chemical composition and dimensions (Adak, Nash and Chen, 2005). Several metals and alloys are used as a clad layer material. Nickel-Aluminum clad material systems are distinguished with intermetallic compounds. The melted part of substrate that mixed with the clad material makes clad layer studies very important (Liang and $\mathrm{Su}, 2000$ ). Thus, one must study all properties that 
are related to clad layer in order to approach the optimum evaluation. Therefore, careful evaluation of clad layers may be used effectively to obtain a successful industrial applications after determination of the required clad layer properties (Steen and Courtney, 1980).

In this work, light will be thrown to illuminate the mixing that occurred between clad layer and substrate material, i.e.dilution percentage in order to control the chemical composition of clad layers of laser cladding of inconel 617 with $\mathrm{Ni}-10 \mathrm{wt} \% \mathrm{Al}$ and $\mathrm{Ni}-30 \mathrm{wt} \% \mathrm{Al}$ premixed powder mixtures under different conditions.

\section{Experimental Work}

A $2 \mathrm{~kW}$, fast axial continuous wave $\mathrm{CO}_{2}$ laser $(10.6 \mu \mathrm{m}$ wavelength) was used to clad different powder mixtures of chemical compositions of $90 \mathrm{wt} \% \mathrm{Ni}(<150 \mu \mathrm{m}$ particle size $)$ and $10 \mathrm{wt} \% \mathrm{Al}(<250 \mu \mathrm{m}$ particle size $)$ and the other was $70 \mathrm{wt} \% \mathrm{Ni}$ and $30 \mathrm{wt} \% \mathrm{Al}$ on the inconel 617 substrate with dimensions of $75 \times 40 \times 5.5 \mathrm{~mm}$. The main laser beam diameter was of approximately $22 \mathrm{~mm}$ which delivered to the substrate by focusing through 150 $\mathrm{mm}$ focal length $\mathrm{KCl}$ lens to obtain a $5 \mathrm{~mm}$ laser beam diameter on the substrate. Argon gas was blown to protect the lens from contamination. The chemical composition and microstructure of inconel 617 substrate were illustrated in Table 1 and Fig. 1 respectively.

The substrate samples were clamped with a suitable jig on a hydraulic powered $\mathrm{x}-\mathrm{y}$ table which was moved relative to the stationary laser beam. The cladding of samples was carried under argon gas as shrouding against contamination from the atmosphere. The laser processing parameters are listed in Table 2. After laser cladding, the features of clad layers such as depth of penetration and clad height were determined from the transverse sections after grinding, polishing and etching. Area dilution as illustrated in Fig.2 can be obtained from the following equation (Bruck, 1980):

$\%$ Area dilution $=\mathrm{A}_{2 /}\left(\mathrm{A}_{1}+\mathrm{A}_{2)} \times 100\right.$

where $A_{1}$ is the area of region (1)

$\mathrm{A}_{2}$ is the area of region (2)

The areas of regions 1 and 2 present in Eq.1 can be calculated using an Image programme. In this programme, standard ruler picture was used to establish measurement scale. After established scale of measurement, the microstructure of clad layers of laser cladding of inconel 617 with $\mathrm{Ni}-10 \mathrm{wt} \% \mathrm{Al}$ and Ni-30 wt $\% \mathrm{Al}$ premixed clad powders of different cladding speeds was inserted to the programme separatly and measurement was taken place. This can be accomplished by determination the region that must be measured.

\section{Results and Discussion}

After the substrate has been wetted with the molten of premixed clad powder, spreading of the melt pool on the substrate will be took place. Spreading can be divided into distinct stages. The first stage is the very rapid spreading under the driving force for the balance of interfacial tensions characteristic of melt pool. In the second stage, the substrate dissolve in the melt pool and forms compounds that nucleate on preferred sites at the solid-liquid interface and later grow to form the reaction product (s). Laser clad layers properties are mainly affected by dilution. Dilution determines the strength of clad layer. Generally, increasing area dilution percentage for specific limit, the bond strength between the clad layer and substrate will be increased too. Dilution is very important property especially in bond strength sensitive applications which are rquiring good wear resistance. In applications which are requiring good corrosion resistance or oxidation resistance, the clad layer composition must be approached that of clad mixture composition. Therefore, theoretically the best quality of clad layer is produced when the clad layer conserve as possible its chemical composition with minimum dilution. Figure. 3 shows the relationship between dilution percentage (D) and cladding traverse speed (V) in which the dilution increases at low and intermediate cladding traverse speeds. At high cladding traverse speed, dilution is decreased as compared with intermediate cladding traverse speed especially for premixed clad powder of Ni-30 wt $\% \mathrm{Al}$. While for premixed clad powder of Ni-10 wt $\% \mathrm{Al}$, dilution continues in increasing rate at high cladding traverse speeds. This can be explained on the basis that at low cladding traverse speeds, melt penetration is high but because of the large thickness of clad layer, minimum melting in the substrate will take place. This means that minimum mixing between premixed clad powder and substrate material occurred. At intermediate cladding traverse speeds, melt penetration is less than that in the low cladding traverse speed, but because the clad height is small, therefore, large melting in the substrate surface will occured. This means that large mixing is taken place and therefore dilution is high. At high cladding traverse speeds, lower melt penetration will take place. The melt penetration, specially for premixed clad powder of $\mathrm{Ni}-30 \mathrm{wt} \% \mathrm{Al}$, does not allow high mixing between clad layer and substrate material to occur, but when compared with mixing at low cladding speeds, it will be high. In preplaced powder laser cladding, the dilution was found to increase with 
decreasing cladding traverse speed. This occurred when the laser beam melts the preplaced powder in order to produce good bonding (Bruck, 1987).

The relationship between dilution percentage (D) and cladding rate $\left(\mathrm{C}_{\mathrm{r}}\right)\left(\mathrm{mm}^{2} / \mathrm{s}\right)$ for premixed clad powders of $\mathrm{Ni}-10 \mathrm{wt} \% \mathrm{Al}$ and $\mathrm{Ni}-30 \mathrm{wt} \% \mathrm{Al}$ is shown in Fig. 4. The relationship between dilution percentage and cladding rate for premixed clad powder o $\mathrm{Ni}-10 \mathrm{wt} \% \mathrm{Al}$ can be expressed as:

$\mathrm{D}=2.72 \mathrm{C}_{\mathrm{r}}^{0.9}$

While for premixed clad powder of $\mathrm{Ni}-30 \mathrm{wt} \% \mathrm{Al}$ this relationship can be expressed as:

$\mathrm{D}=0.015 \mathrm{C}_{\mathrm{r}}^{1.07}$

The dilution percentage is increased with increasing cladding rate (increases in cladding traverse speed). This is because with increasing cladding rate, any small heat input with respect to the clad height at a given cladding rate is considered high; therefore, dilution is high. It is clear from Fig.6 that no decreasing in dilution percentage took place at high cladding rate as compared with the relationship between dilution percentage and cladding speed for premixed clad powder of Ni-30 wt $\% \mathrm{Al}$ (Fig. 4). This is because at high cladding traverse speed, the magnitude of cladding rate decreases due to decrease in the clad width. As a result of dilution at higher cladding rate for premixed clad powder of $\mathrm{Ni}-30 \mathrm{wt} \% \mathrm{Al}$ is low (19.7\%) compared with previous dilution percentage (41\%); it approached in magnitude of the cladding rate at cladding traverse speed of $3.2 \mathrm{~mm} / \mathrm{s}$ which is $23.1 \%$. Therefore, the decreasing in dilution percentage at high cladding rate does not appear on the graph (Fig. 4).

Conversely, the relationship between dilution percentage and specific energy (Fig. 5) shows that the dilution is increased exponentially with deceasing specific energy (increasing cladding speed). The relationship between dilution percentage (D) and specific energy (E) $\left(\mathrm{J} / \mathrm{mm}^{2}\right)$ for premixed clad powder of $\mathrm{Ni}-10 \% \mathrm{Al}$ can be expressed as:

$\mathrm{D}=71.5 \mathrm{e}^{-0.009 \mathrm{E}}$

While for premixed clad powder of $\mathrm{Ni}-30 \% \mathrm{Al}$ this relationship can be expressed as:

$\mathrm{D}=0.41 \mathrm{e}^{-0.0067 \mathrm{E}}$

5

Increasing the dilution percentage with decreasing in specific energy is related to increase in the cladding traverse speed with decreasing in specific energy. Decreasing cladding traverse speed means that little mixing will take place between premixed clad powder and substrate. Therefore, dilution is low.

\section{Conclusions}

1) Laser cladding of inconel 617 substrate with $\mathrm{Ni}-10 \mathrm{wt} \% \mathrm{Al}$ and $\mathrm{Ni}-30 \mathrm{wt} \% \mathrm{Al}$ premixed clad powders is feasible to obtain new high quality surface layer.

2) Experiments on laser cladding indicate that single clad layers of $\mathrm{Ni}-10 \mathrm{wt} \% \mathrm{Al}$ and $\mathrm{Ni}-30 \mathrm{wt} \% \mathrm{Al}$ premixed clad powders with dilution ranging from 3.7 to $78.3 \%$ and 6.9 to $41 \%$ respectively can be obtained.

3) The results showed that dilution is dependent mainly on cladding traverse speed with respect to constant of other laser cladding process variables.

\section{References}

Adak, B., Nash, P and Chen, D. (2005). Microstructural characterization of laser cladding of Cu-30Ni, J. Materials Science, 40, 2051.

Bruck, G.J. (1987). High power laser beam cladding, J of Metals, 39, 10.

Das, S.K and Davis, L.A. (1988). High performance aerospace alloys via rapid solidification processing, Materials Science Engineering, 98, 1.

Jendrzejewskia, R., Condeb, A., de Damboreneab, J and Sliwinski, G. (2002). Characterization of the laser-clad stellite layers for protective coatings, Materials Design, 23, 83.

Liang, G.Y and Su, J.Y. (2000). The microstructure and tribological characteristics of laser-clad $\mathrm{Ni}-\mathrm{Cr}-\mathrm{Al}$ coatings on aluminum alloy, Materials Science and Engineering A, 290, 207.

Maiman, T.H. (1960). Stimulated optical radiation in ruby, Nature, 187, 493.

Manna, I., Majumdar, J.D., Chandra, B.R., Nayak, S and Dahotre, N.B (2006). Laser surface cladding of $\mathrm{Fe}-\mathrm{B}-\mathrm{C}, \mathrm{Fe}-\mathrm{B}-\mathrm{Si}$ and $\mathrm{Fe}-\mathrm{BC}-\mathrm{Si}-\mathrm{Al}-\mathrm{C}$ on plain carbon steel, Surface Coating Technology, 201, 434.

Nenadovć, T.M (2002). Hyperfine surface structure, Materiali in Technologije, 36, 91. 
Steen, W.M and Courtney, C.G.H. (1980). Hardfacing of nimonic 75 using $2 \mathrm{~kW}$ continuous wave $\mathrm{CO}_{2}$ laser, Metals Technology, June, 232.

Yang, Y. (1999). Microstructure and properties of laser-clad high-temperature wear-resistant alloys, Applied Surface. Science, 140, 19.

Table 1. Chemical composition of inconel 617

\begin{tabular}{|c|c|c|c|c|c|c|c|}
\hline \multicolumn{8}{|c|}{ Chemical composition, wt\% } \\
\hline $\mathrm{Fe}$ & $\mathrm{Cr}$ & $\mathrm{Mo}$ & $\mathrm{Co}$ & $\mathrm{Ti}$ & $\mathrm{Si}$ & $\mathrm{Al}$ & $\mathrm{Ni}$ \\
\hline 1.25 & 21.7 & 8.9 & 12.4 & 0.45 & 0.06 & 0.73 & 54.1 \\
\hline
\end{tabular}

Table 2. Processing parameters studied

\begin{tabular}{ll}
\hline Power $(\mathrm{p})$ & $1.7-1.9 \mathrm{~kW}$ \\
Beam diameter $(\mathrm{d})$ & $5 \mathrm{~mm}$ \\
Traverse speed $(\mathrm{V})$ & $1-35 \mathrm{~mm} / \mathrm{s}$ \\
Interaction time $(\mathrm{t})$ & $0.14-5 \mathrm{~s}$ \\
Power density $\left(4 \mathrm{P} / \pi \mathrm{d}^{2}\right)\left(\mathrm{P}_{\mathrm{A}}\right)$ & $86-97 \mathrm{~W} / \mathrm{mm}^{2}$ \\
Specific energy $(\mathrm{P} / \mathrm{dV})$ & $9.7-380 \mathrm{~J} / \mathrm{mm}^{2}$ \\
Powder feed rate $(\mathrm{f})$ & $8.9-10 \mathrm{~g} / \mathrm{min}^{2}$ \\
Shrouding gas & Argon \\
\hline
\end{tabular}

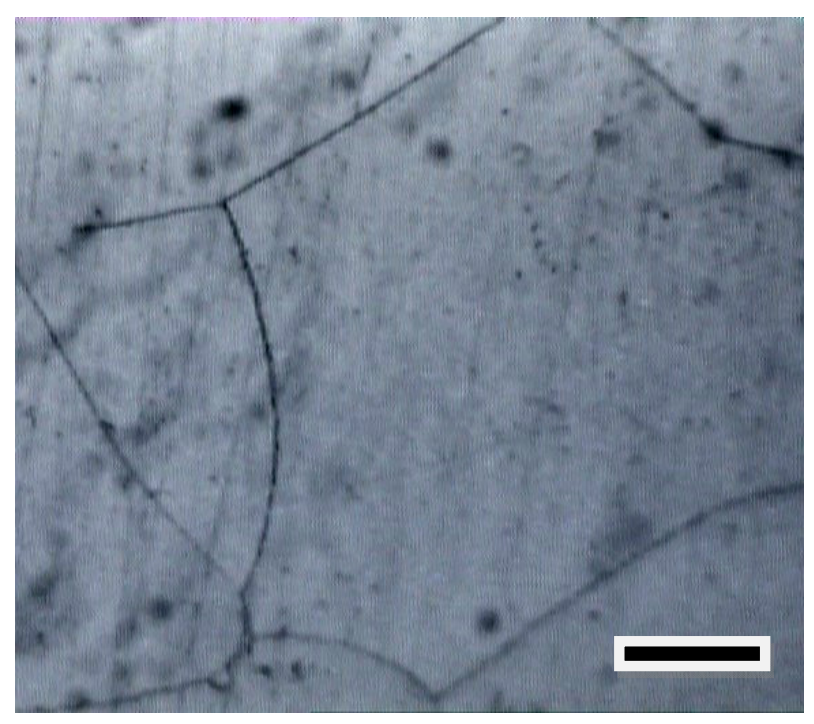

Figure 1. Microstructure of the inconel 617 substrate (marker is $15 \mu \mathrm{m}$ ). 


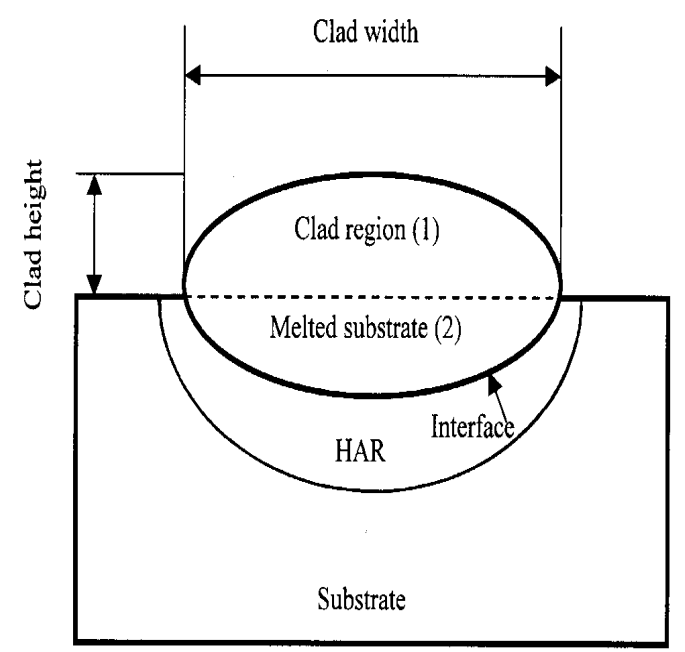

Figure 2. Schematic shape of the laser clad layer.

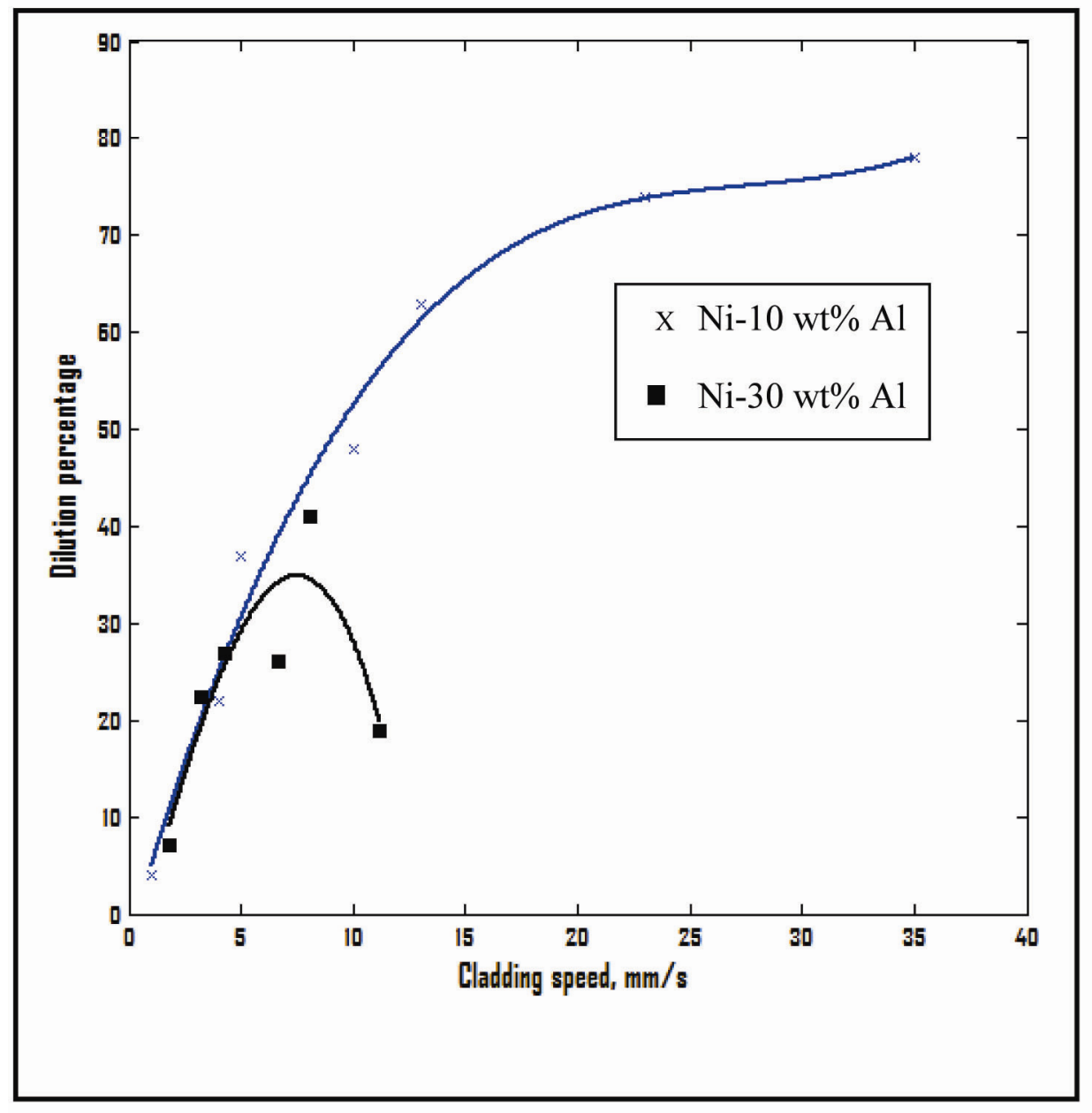

Figure 3. The relationship between dilution percentage and cladding traverse speed of laser cladded inconel 617 with $\mathrm{Ni}-10 \mathrm{wt} \% \mathrm{Al}$ and $\mathrm{Ni}-30 \mathrm{wt} \% \mathrm{Al}$ premixed powders 


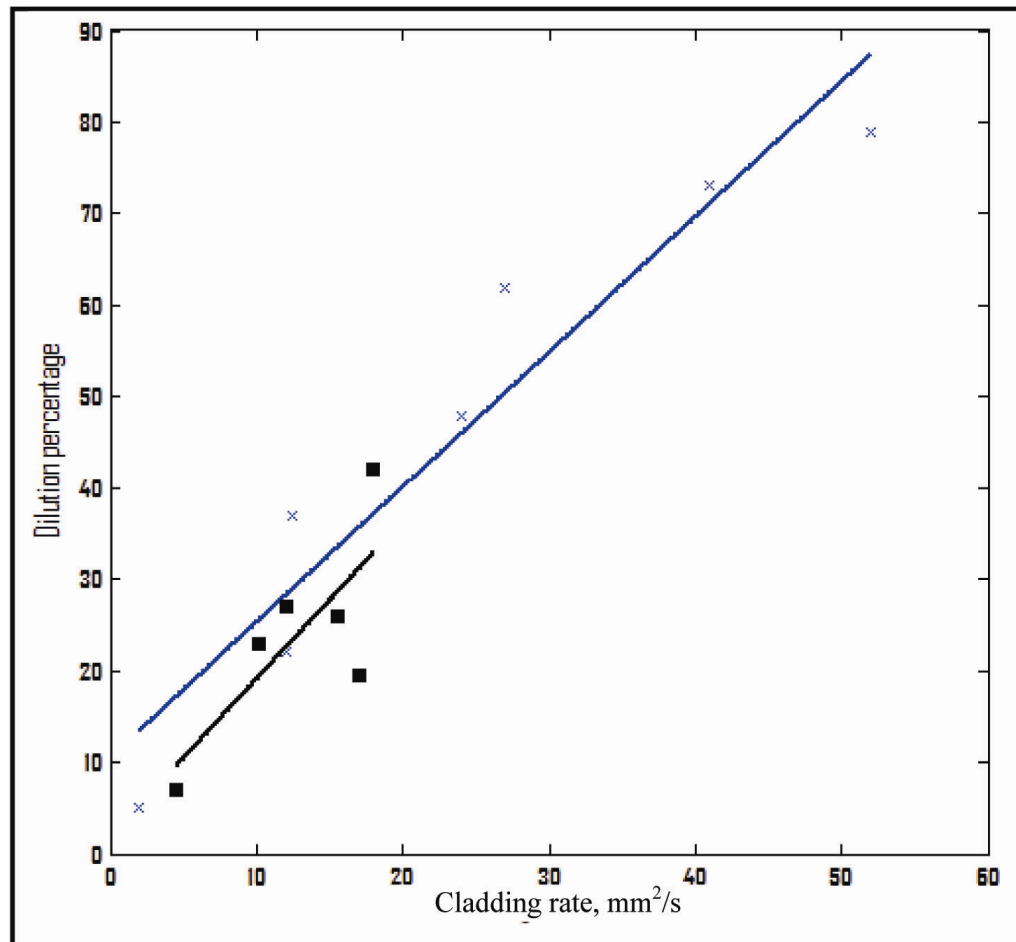

Figure 4. The relationship between dilution percentage and cladding rate of laser cladded inconel 617 with Ni-10 $\mathrm{wt} \% \mathrm{Al}$ and $\mathrm{Ni}-30 \mathrm{wt} \% \mathrm{Al}$ premixed powders.

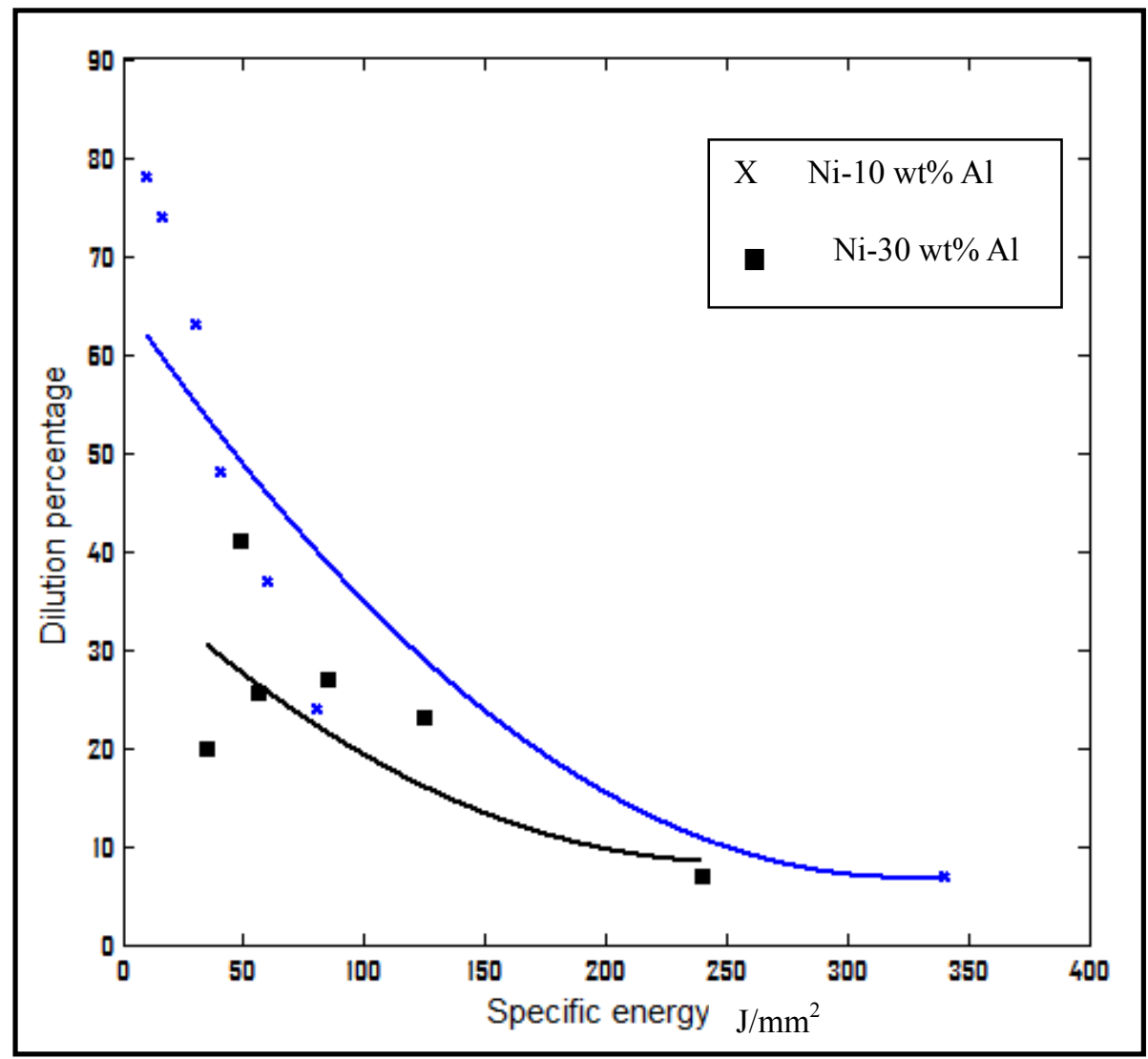

Figure 5. The relationship between dilution percentage and specific energy of laser cladded inconel 617 with $\mathrm{Ni}-10 \mathrm{wt} \% \mathrm{Al}$ and $30 \mathrm{wt} \% \mathrm{Al}$ premixed powders. 